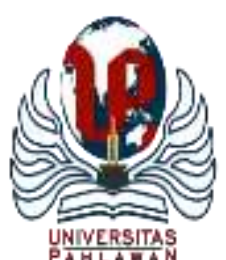

\title{
JURNALBASICEDU
}

Volume 6 Nomor 1 Tahun 2022 Halaman 1376 - 1388

Research \& Learningin Elementary Education

https://jbasic.org/index.php/basicedu

\section{Program Tutorial Mata Kuliah Etika Kristen sebagai Pembentukan Konsep Diri Mahasiswa}

\author{
Esther Rela Intarti ${ }^{1}$, Noh Ibrahim Boiliu ${ }^{2 \bowtie}$
}

Program Studi Pendidikan Agama Kristen, Universitas Kristen Indonesia, Indonesia ${ }^{1,2}$

E-mail: esintarti@yahoo.com ${ }^{1}$, boiliunoh@gmail.com ${ }^{2}$

\begin{abstract}
Abstrak
Dalam melaksanakan tugas dan tanggung jawab sebagai institusi pendidikan, Universitas Kristen Indonesia (UKI) tentu dituntut untuk mendidik para mahasiswa agar para mahasiswa dapat menjadi manusia yang utuh, berilmu, cerdas, tangguh, dan berkarakter. Upaya untuk membangun manusia yang tangguh dan berkarakter ini sejalan dengan nilai-nilai kekristenan yang seharusnya dipahami oleh para mahasiswa. Untuk mengimplementasikan nilai-nilai kristiani bagi para mahasiswa. Unit Pelayanan Kerohanian dan Konseling (UPKK) UKI melalui mata kuliah Etika Kristen membuat program tutorial etika kristen yang bertujuan agar mahasiswa mengenali konsep diri dan memahami tujuan hidup yang bermakna sehingga menjadi manusia yang tangguh dan berkarakter sesuai dengan nilai-nilai kristiani. Penelitian ini dilakukan untuk mengetahui program tutorial etika Kristen dapat bermanfaat dan diterima oleh para mahasiswa Berdasarkan hasil analisis bahwa rancangan program tutorial mata kuliah Etika Kristen ini terstruktur dengan baik sehingga berdampak positif bagi para mahasiswa. Program tutorial mata kuliah Etika Kristen di UKI diperuntukkan bagi mahasiswa baru. Metode yang digunakan dalam penelitian ini adalah metode kualitatif deskriptif.
\end{abstract}

Kata Kunci: Program Tutorial, Etika Kristen, Konsep Diri, Mahasiswa.

\begin{abstract}
The Christian University of Indonesia tries to answer these challenges through the implementation of Christian values for students at UKI. The Spiritual Services and Counseling Unit (UPKK) takes on this role by providing mentoring and coaching tutorials through the Christian Ethics course. The purpose of this study was to determine the positive roles of UPKK, assistant tutors, and lecturers of Christian Ethics in helping students recognize self-concepts. The method used in this research is descriptive qualitative method. Based on the results of the analysis, it was found that the tutorial program for the Christian Ethics subject held by the Indonesian Christian University had run well, was effective and had a positive role; The Christian Ethics tutorial program at UKI has been well designed; the Christian Ethics tutorial program at UKI helps students to better identify themselves; UKI's Christian Ethics tutorial program helps students find a purpose in life that is meaningful and meaningful to their life; The Christian Ethics tutorial program at UKI is the first community for UKI New Students to form their self-concept that is correct based on Christian values.
\end{abstract}

Keywords: Tutorial Program, Christian Ethics, Self Concept, Student.

Copyright (c) 2022 Esther Rela Intarti, Noh Ibrahim Boiliu

$\triangle$ Corresponding author :

Email : boiliunoh@gmail.com

DOI $\quad$ : https://doi.org/10.31004/basicedu.v6i1.1721

ISSN 2580-3735 (Media Cetak)

ISSN 2580-1147 (Media Online)

Jurnal Basicedu Vol 6 No 1 Tahun 2022

p-ISSN 2580-3735 e-ISSN 2580-1147 
1377 Program Tutorial Mata Kuliah Etika Kristen sebagai Pembentukan Konsep Diri Mahasiswa - Esther Rela Intarti, Noh Ibrahim Boiliu

DOI: https://doi.org/10.31004/basicedu.v6i1.1721

\section{PENDAHULUAN}

UKI adalah sebuah universitas yang mempunyai kekhasan dalam identitasnya yaitu kampus Kristen. Kekristenan memberikan sebuah identitas yang harus diwujudnyatakan dalam mendidik para mahasiswa yang telah dipercayakan bagi UKI. Kekristenan hendaknya menjadi sebuah nilai yang seharusnya dapat dipahami dalam berbagai lini kehidupan kampus UKI. Nilai-nilai Kristiani harus nyata diimplementasikan pada kehidupan akademis di kampus UKI. Untuk itu, sosialisasi kehidupan Kristen harus secara nyata dimulai sejak awal pada saat mahasiswa baru UKI diterima di UKI. Para mahasiswa baru UKI tentunya terdiri dari latar belakang yang berbeda, baik agama, budaya, sosial, suku dan tentunya pendidikan dalam keluarga dan lingkungan sebelumnya mereka masuk ke UKI. Demikian pula secara psikologis para mahasiswa baru tentu merasakan adanya perbedaan baik situasi maupun kondisi dalam lingkungan yang baru dengan keadaan sebelumnya. Selain itu, adanya tradisi senioritas yang menjadi sebuah fenomena nyata di beberapa fakultas di UKI sehingga mahasiswa baru seringkali menjadi korban bullying. Hal ini dialami mahasiswa baru melalui tekanan untuk menuruti perintah senior dengan berbagai perintah yang kurang jelas, diantaranya diajak nongkrong sampai malam, minum-minuman berakohol, mengerjakan tugas-tugas senior. Hal tersebut berakibat cara pandang dan relasi mahasiswa baru kepada mahasiswa senior/mahasiswa di atas angkatannya kurang baik. Padahal, seorang mahasiswa senior harus menjadi role model bagi mahasiswa yunior. Realitas ini tentu memberikan citra negatif bagi Universitas Kristen Indonesia Jakarta. Ini bertolak belakang dengan prinsip UKI sebagai kampus kasih.

Pada penelitian terdahulu di tahun 2014, Indah Puspasari Kiay Demak dan Etwien Reskinta Paulus (Demak \& Paulus, 2014) melakukan penelitian untuk mengetahui Hubungan Persepsi Mahasiswa Terhadap Peran Tutor Pada Tutorial dengan Prestasi Belajar di Program Studi Pendidikan Dokter Fakultas Kedokteran dan Ilmu Kesehatan Universitas Tadulako. Keduanya menggunakan pendekatan cross sectional dengan uji Chi-square. Hasilnya adalah tidak terdapat hubungan yang signifikan antara persepsi mahasiswa terhadap peran tutor dengan prestasi belajar mahasiswa. Pada penelitian lain yang dilakukan oleh Febri Annisaa Nuurjannah (Nuurjannah, 2020) pada tahun 2020 untuk mengetahui Hubungan Pelaksanaan Metode Pembelajaran Tutorial dengan Kemampuan Berpikir Kritis Mahasiswa di Program Studi D3 Kebidanan Unpad, dengan pendekatan kuantitatif. Hasilnya, terdapat hubungan yang signifikan antara metode pembelajaran tutorial dengan kemampuan berpikir kritis mahasiswa. Berdasarkan kedua penelitian terdahulu penelitian pertama untuk variabel $\mathrm{X}$ difokuskan pada Peran Tutor (tute) sedangkan varibel $\mathrm{X}$ untuk penelitian kedua fokus pada metode tutorial. Pada varibel Y, penelitan pertama mengetahui apakah ada hubungan antara peran tutor dengan hasil belajar, sedangkan penelitian kedua ingin mengetahui hubungan antara metode tutor dengan berpikir kritis. Artinya kedua penelitian ini juga berbeda, baik variabel, lokus, dan hasil. Sedangkan dalam penelitian Program Tutorial Mata Kuliah Etika Kristen sebagai Pembentukan Konsep Diri Mahasiswa sama dengan dua penelitian terdahulu pada Tutorial namun berbeda dari kedua penelitian terdahulu dari segi fokus, metode, dan lokus, sebab program tutorial menyangkut aspek metode, totor (tute) sebagai pendekatan dalam pembentukan konsep diri mahasiswa. Artinya, kedua penelitian terhulu fokus pada aspek kognitif sedangkan penelitian yang dilakukan penulis/penelitian ini fokus pada afeksi dan psikomotorik.

Pengertian "tutorial" dalam Kamus Besar Bahasa Indonesia diartikan pembimbingan kelas oleh seorang pengajar (tutor) untuk seorang mahasiswa atau sekelompok kecil mahasiswa; pengajaran tambahan melalui tutor (Badan Pengembangan Bahasa dan Perbukuan, 2016, bnd. Suroso, 1992). Amos Neolaka, \& Grace Amialia A. Neolaka $(2017,254)$ mengatakan prinsip tutorial telah diperkenalkan oleh John Amos Comenius tokoh Pendidikan Agama Kristen yang mengatakan "He who teaches others teaches himself" atau siapa mengajar yang lain ia mengajar dirinya sendiri (Harsono et al., 2005). Hal tersebut merupakan cara mengembangkan penguasaan materi atau bahan ajar yang lebih menguntungkan kedua belah pihak yaitu tutor 
1378 Program Tutorial Mata Kuliah Etika Kristen sebagai Pembentukan Konsep Diri Mahasiswa - Esther Rela Intarti, Noh Ibrahim Boiliu

DOI: https://doi.org/10.31004/basicedu.v6i1.1721

dan tutee atau tutor dan yang ditutori. Pengembangan penguasaan materi ajar merupakan kerangka prosedural pembelajaran yang menitikberatkan pada bimbingan dan bantuan belajar oleh guru atau sesama peserta didik.

Amos dan Grace memberikan indikator yang jelas bahwa bimbingan dan bantuan dimaksudkan agar sesama pembelajar saling memberikan stimulus dan saling meningkatkan intensitas belajar, serta menciptakan suasana belajar yang dinamis dan demokratis. Hal ini diperjelas oleh Oemar Hamalik (1994, 73), yang mengatakan tutorial adalah bimbingan pembelajaran dalam bentuk pemberian bimbingan, bantuan, petunjuk, arahan, dan motivasi agar para siswa belajar secara efisien dan efektif. Hal tersebut dapat berarti membantu siswa dalam mempelajari materi modul. Petunjuk berarti memberikan makna cara belajar secara efisien dan efektif. Arahan berarti mengarahkan para siswa untuk mencapai tujuan masing-masing modul. Motivasi berarti menggerakkan kegiatan para siswa dalam mempelajari modul, mengerjakan tugas-tugas, dan mengikuti penilaian. Bimbingan berarti membantu para siswa memecahkan masalah-masalah belajar seperti yang dikatakan Schmidt dan Bouhuijs dalam Cahyono (Cahyono, 2004).

Prinsip yang sama juga dikemukakan oleh Neny Triana $(2018,54)$ bahwa penyelenggaraan tutor yang efektif, dan tidak terjebak pada situasi untuk dipahami oleh tutor, adalah: 1) Interaksi tutorial sebaiknya berlangsung pada tingkat metakognitif, yaitu tingkat berpikir yang menekankan pada pembentukan ketrampilan "learning how to learn" atau "think how to think". 2) Tutorial harus memiliki langkah proses belajar yang dijalani oleh tutee; 3) Tutorial harus mampu mendorong tutee sampai pada taraf pengertian yang mendalam sehingga mampu menghasilkan pengetahuan yang tahan lama; 4) segala keputusan dalam tutorial sebaiknya diambil melaui proses dinamika kelompok di mana tutee dalam kelompok memberikan sumbangan pikirannya; 5) Tutorial harus mampu membuat variasi stimulasi/ransangan untuk belajar, sehingga tutee tidak merasa bosan, jenuh dan putus asa; 6) Tutorial selayaknya memantau kualitas kemajuan belajar tutee dengan mengarahkan kajian sampai pada taraf pengertian yang mendalam. Maksudnya adalah tujuan tutorial membuat siswa mandiri. Rudy Dumoharsono dan Hisbiyatul Hassanah $(2018,88)$ mengatakan, tutorial sama dengan program bimbingan yang bertujuan memberikan bantuan kepada siswa secara optimal yang berarti siswa dapat melaksanakan kegiatan belajar secara mandiri.

Pertanyaannya adalah apa fungsi tutorial jika dikaitkan dengan pembelajaran? Oemar Hamalik (1994, 158-160) menjelaskan tentang fungsi tutorial meliputi, instruksional, yakni melaksanakan proses pembelajaran agar para siswa belajar mandiri melalui modul yang telah ditetapkan, diagnosis-bimbingan yakni membantu para siswa mengalami kelemahan, kekuatan, kelambanan, masalah dalam mempelajari modul berdasarkan hasil penilaian, baik formatif, maupun sumatif, sehingga siswa siswa mampu membimbing diri sendiri; personal, yakni memberikan keteladanan kepada siswa seperti penguasaan materi modul, cara belajar, sikap dan perilaku yang secara tak langsung menggugah motivasi belajar mandiri dan motif berprestasi.

Fungsi tutorial seperti di atas mengindikasikan bahwa kegiatan tutorial merupakan suatu rencana atau program yang dibuat secara professional dan terukur agar dapat dilihat hasilnya serta memiliki tujuan yang jelas. Tujuan tersebut yang akan dijadikan indikator bagi proses pembelajaran sebagaimana yang dikatakan Oemar Hamalik menjelaskan dari segi tujuan adalah:

1. Untuk meningkatkan penguasaan pengetahuan para siswa sesuai dengan yang dimuat modul-modul: melakukan usaha-usaha pengayaan materi yang relevan.

2. Untuk meningkatkan keterampilan siswa tentang cara memecahkan masalah, mengatasi kesulitan atau hambatan agar mampu membimbing diri sendiri.

3. Untuk meningkatkan kemampuan siswa tentang cara belajar mandiri dan menerapkannya pada masingmasing modul yang sedang dipelajari.

Dari penjelasan tersebut maka dapat ditarik kesimpulan bahwa tutorial dapat meningkatkan performa mahasiswa dalam proses pembelajaran selama kuliah secara mandiri. 
1379 Program Tutorial Mata Kuliah Etika Kristen sebagai Pembentukan Konsep Diri Mahasiswa - Esther Rela Intarti, Noh Ibrahim Boiliu

DOI: https://doi.org/10.31004/basicedu.v6i1.1721

Konsep diri merupakan cara pandang seseorang terhadap diri terbentuk bukan saja muncul tiba-tiba (MacKenna, 2002), namun terbentuk melalui sebuah proses dari lingkungan terhadap diri manusia (Gebauer et al., 2017). G. Terry Paul dan Thomas Paul dalam Kurniawan bahwa konsep diri merupakan kesatuan susunan persepsi-persepsi yang disadari serta individu yang menurutinya (Kurniawan, 2000), demikian juga cara pandang manusia terhadap dirinya tidak lepas dari keyakinan akan imannya kepada Tuhan yang dipercaya (Thornton, 1985). Konsep diri juga merupakan tanggapan seseorang melalui faktor yang dijiwai dan terbentuk melalui pengalaman individu dalam berhubungan dengan individu lain (Situmorang et al., 2020). Melalui keyakinan iman manusia pada akhirnya mampu memandang dirinya dengan mengaitkan cara pandang manusia dengan ajaran Tuhan terhadap dirinya sebagai umat ciptaan di hadapan Tuhan Sang Pencipta (Bettler, 1984). Berkait dengan iman Kristen sangat jelas dan nyata dalam Alkitab bahwa manusia ditempatkan sangat mulia dan agung dengan diberikan suatu tempat yang sangat tinggi seperti dalam Mazmur 8: 3-6, "Jika aku melihat langit-Mu, buatan jari-Mu, bulan dan bintang-bintang yang Kau tempatkan: apakah manusia manusia sehingga Engkau mengingatnya? Apakah anak manusia sehingga Engkau mengindahkannya? Namun Engkau telah membuatnya hampir sama seperti Allah, dan memahkotainya dengan kemuliaan dan hormat. Engkau membuat dia berkuasa atas buatan tangan-Mu, segala-galanya telah Kau letakan dibawah kakinya". Demikian mulia pandangan Allah terhadap manusia, meskipun manusia hanya diciptakan dan tersusun dari debu tanah (Kej. 2: 7; bnd. (Kurniawan, 2000).

Stephen Tong (2009, 1-24; Wells, 1983) menyatakan, Alkitab menunjukkan betapa pentingnya setiap orang percaya memiliki konsep diri yang seimbang, yaitu antara keluhuran atau kemuliaan (dignity) dan kerendahan (humility) yang dimiliki manusia (bnd. Maksudnya dalam satu sisi manusia adalah mahkluk yang rendah karena hanya tercipta dari debu dan sisi lain manusia adalah gambar Allah (Kej. 1: 26-27) yang menunjukkan satu keluhuran (N. I. Boiliu et al., 2020; Norman, 1977).

Melihat dua sisi dalam diri manusia antara kerendahan dan keluhuran maka diperlukan keseimbangan dalam cara pandang manusia terhadap dirinya (Jordan et al., 2015). Pandangan ini sangat realistis karena memang manusia tidak ada yang sempurna dalam dirinya. Pandangan yang realistis ini seharusnya membawa manusia pada satu kesadaran tidak terjebak pada satu posisi yang dominan sehingga membentuk cara pandang yang mengarah pada superioritas atau sebaliknya inferioritas (Szcześniak \& Timoszyk-Tomczak, 2020). Manusia seharusnya menyadari keberadaan dirinya di hadapan Tuhan dengan menyadari siapa dirinya, mengenali identitas dirinya berdasarkan pandangan Tuhan (Dupe, 2020) sehingga dapat mengaktualisasikan diri (Awang et al., 2021). Aktualisasi diri dapat dilihat melalui karakter dalam kesehariannya (Matondang, 2018; Marija et al., 2019).

Manusia diciptakan segambar dengan Allah (Kej. 1: 1,7). Hal ini sangat jelas menyatakan bahwa semua ciptaan termasuk manusia sepenuhnya tergantung pada kehendak Sang Pencipta (N. I. Boiliu et al., 2020). Demikian pula seperti penjelasan Paulus (Kis. 17: 25,28) bahwa hanya Allah-lah yang memberikan hidup dan nafas dan segala sesuatu kepada semua orang dan bahwa di dalam Dia kita hidup, kita bergerak, kita ada, namun menurut Anthony A. Hoekema $(2018,8)$ bahwa manusia bukan sekedar sebuah ciptaan, ia juga adalah satu pribadi. Menjadi satu pribadi berarti mampu membuat keputusan, menetapkan tujuan, dan bergerak ke arah tujuan-tujuan itu. Hal ini berarti manusia memiliki kebebasan (N. I. Boiliu \& Samosir, 2019). Setidaknya dalam arti ia mampu membuat pilihan-pilihannya sendiri. Manusia bukan robot yang tindakannya ditentukan secara total oleh kekuatan-kekuatan di luar dirinya, ia memiliki kekuatan untuk menentukan dan mengarahkan diri sendiri, sebab ia mengenali diri (Awang et al., 2021). Dengan demikian, menjadi satu pribadi berarti menjadi ciptaan yang memiliki pilihan. Dari pemahaman ini dapat dikatakan bahwa manusia meski sebagai ciptaan dan bergantung kepada pencipta-Nya bukan berarti sepenuhnya segala sesuatu ditentukan Allah, tetapi manusia juga diberikan kebebasan untuk menentukan pilihannya. Pilihan-pilihan yang dibuat menunjukkan identitas diri yang ditemukan didalam Allah (bnd. (Awang et al., 2021). Gambar diri 
1380 Program Tutorial Mata Kuliah Etika Kristen sebagai Pembentukan Konsep Diri Mahasiswa - Esther Rela Intarti, Noh Ibrahim Boiliu

DOI: https://doi.org/10.31004/basicedu.v6i1.1721

yang dibangun di atas konsep segambar dan serupa Allah, memampukan manusia untuk memainkan perannya seperti yang diungkapkan Secor (Secor, 2020).

Bedasarkan latar belakang masalah di atas maka peneliti merasa sangat penting melakukan suatu riset yang membahas tentang "Program Tutorial Mata Kuliah Etika Kristen sebagai Pembentukan Konsep Diri Mahasiswa Universitas Kristen Indonesia”.

\section{METODE PENELITIAN}

Penelitian ini direncanakan akan dilakukan di Universitas Kristen Indonesia (UKI) Jakarta, Cawang Jakarta Timur selama 6 bulan, dimulai bulan Januari sampai dengan Juni 2020. Metode penelitan yang digunakan adalah metode kualitatif deskriptif (Moleong, 2018). Prosedur penelitian yang dilakukan adalah tahap pra penelitian, studi literatur, menyusun rancangan penelitian, pelaksanaan penelitian, penyebaran angket, analisis data dan pembahasan, dan diakhiri dengan presentasi hasil di LPPM UKI. Responden dalam penelitian ini adalah mahasiswa UKI dari 11 Program Studi dan 3 orang karyawan UKI terdiri dari: 2 Tenaga Pendidik yang terlibat dalam kegiatan Tutorial Etika dan 1 orang Tenaga Kependidikan.

Metode pengumpulan data yang digunakan dalam penelitian ini adalah berupa angket. Untuk penyebaran angket melalui google form kepada 16 orang mahasiswa Universitas Kristen Indonesia - Jakarta yang mengambil program tutorial mata kuliah Etika Kristen, namun yang mengisi angket hanya 16 orang. Selanjutnya hasil tanggapan dari ke-16 orang mahasiswa tersebut dianalisis secara deskriptif yaitu peneliti mendeskripsikan setiap data karakteristik responden yang berupa jenis kelamin, usia, dan program studi. Selanjutnya, ke-3 karyawan diwawancarai untuk dikonfirmasikan dengan hasil analisis terhadap 16 responden dari mahasiswa.

\section{HASIL DAN PEMBAHASAN}

Dalam penelitian ini, peneliti telah mengumpulkan informasi dari 16 orang responden yaitu mahasiswamahasiswi yang telah mengikuti program tutorial mata kuliah Etika Kristen yang diselenggarakan oleh Universitas Kristen Indonesia. Berdasarkan hasil analisis deskriptif terhadap variabel Program Tutorial Mata Kuliah Etika Kristen diperoleh rata-rata skor sebesar 3.16. Skor ini menunjukkan bahwa responden rata-rata memilih setuju dengan program tutorial yang diadakan oleh pihak kampus. Tentunya program ini sangat bermanfaat bagi mereka sehingga mayoritas responden memberikan response yang baik atas program tersebut.

Untuk hasil analisis deskriptif profile responden yang terdiri dari jenis kelamin, usia dan program studi, dapat dilihat pada tabel di bawah ini:

Tabel 1. Karakteristik Responden Berdasarkan Jenis Kelamin

\begin{tabular}{|c|c|c|c|c|}
\hline No & & Description & Frequency & Percent \\
\hline \multirow[t]{3}{*}{1} & Jenis Kelamin & Laki-laki & 4 & 25.0 \\
\hline & & Perempuan & 12 & 75.0 \\
\hline & & Total & 16 & 100.0 \\
\hline \multirow[t]{4}{*}{2} & Usia & $\leq 16$ Tahun & 0 & 0,0 \\
\hline & & 16 - 20 Tahun & 4 & 25.0 \\
\hline & & $>20$ Tahun & 12 & 75.0 \\
\hline & & Total & 16 & 100.0 \\
\hline & Program Studi & Akuntansi & 1 & 6.3 \\
\hline & & Biologi & 1 & 6.3 \\
\hline & & Fisioterapi & 1 & 6.3 \\
\hline & & Manajemen & 1 & 6.3 \\
\hline & & Matematika & 2 & 12.5 \\
\hline
\end{tabular}


1381 Program Tutorial Mata Kuliah Etika Kristen sebagai Pembentukan Konsep Diri Mahasiswa - Esther Rela Intarti, Noh Ibrahim Boiliu

DOI: https://doi.org/10.31004/basicedu.v6i1.1721

\begin{tabular}{llrr}
\hline No & Description & Frequency & Percent \\
\hline \multirow{2}{*}{$\begin{array}{c}\text { Pendidikan Agama } \\
\text { Kristen }\end{array}$} & 3 & 18.8 \\
\cline { 2 - 4 } & Pendidikan Fisika & 2 & 12.5 \\
\cline { 2 - 4 } & Pendidikan Kimia & 1 & 6.3 \\
\cline { 2 - 4 } & Perbankan & 1 & 6.3 \\
\cline { 2 - 3 } & Perpajakan & 1 & 6.3 \\
\cline { 2 - 3 } & Teknik Elektro & 2 & 12.5 \\
\cline { 2 - 3 } & Total & $\mathbf{1 6}$ & $\mathbf{1 0 0 . 0}$ \\
\hline
\end{tabular}

Sumber: Data Primer Diolah 2020.

Berdasarkan hasil analisis deskriptif tentang profile responden, menunjukkan bahwa responden yang berjenis kelamin laki-laki sebanyak 4 orang $(25,0 \%)$ dan responden yang berjenis kelamin perempuan sebanyak 12 orang $(75,0 \%)$. Jumlah tersebut menunjukkan bahwa mayoritas responden yang mengikuti program tutorial di Universitas Kristen Indonesia adalah responden yang berjenis kelamin perempuan. Sedangkan rata-rata usia responden dalam penelitian ini adalah responden yang berusia di atas 20 tahun sebanyak 75 orang $(75,0 \%)$, dan disusul dengan responden yang berusia antara 16-20 tahun sebanyak 4 orang $(25,0 \%)$. Selanjutnya, berdasarkan hasil analisis deskriptif yang dilakukan diperoleh informasi bahwa responden yang mengisi kuesioner ini terdiri dari 11 program studi yaitu program studi pendidikan agama Kristen sebanyak 3 mahasiswa $(18,8 \%)$ dan program studi matematika, pendidikan fisika dan teknik elektro masing-masing 2 mahasiswa (12,5\%), sedangkan program studi akuntansi, biologi, fisioterapi, manajemen, pendidikan kimia, perbankan, perpajakan masing-masing hanya 1 mahasiswa $(6,3 \%)$

Dalam penelitian ini, peneliti telah mengumpulkan informasi dari 16 orang responden yaitu mahasiswamahasiswi yang telah mengikuti program tutorial mata kuliah Etika Kristen yang diselenggarakan oleh Universitas Kristen Indonesia. Untuk hasil tanggapan para mahasiswa-mahasiswi tersebut dapat di lihat pada tabel di bawah ini:

Tabel 2. Variabel Program Tutorial Mata Kuliah Etika Kristen

\begin{tabular}{|c|c|c|c|c|c|c|c|}
\hline No. & Program Tutorial Mata Kuliah Etika Kristen & $\begin{array}{c}\text { ST } \\
\text { S } \\
\text { (1) }\end{array}$ & $\begin{array}{l}\text { TS } \\
(2)\end{array}$ & $\begin{array}{c}\text { S } \\
(3)\end{array}$ & $\begin{array}{l}\text { SS } \\
(4)\end{array}$ & $\begin{array}{l}\text { To } \\
\text { tal }\end{array}$ & $\begin{array}{c}\text { Rat } \\
\text { a- } \\
\text { rat } \\
\text { a } \\
\text { sko } \\
\text { r }\end{array}$ \\
\hline 1.1 & $\begin{array}{l}\text { Program tutorial mata kuliah Etika Kristen yang diadakan oleh } \\
\text { kampus UKI sangat bermanfaat bagi saya. }\end{array}$ & $\mathbf{0}$ & $\mathbf{0}$ & 2 & 14 & 62 & $\begin{array}{c}3.8 \\
8\end{array}$ \\
\hline 1.2 & $\begin{array}{l}\text { Program tutorial mata kuliah Etika Kristen yang diadakan oleh } \\
\text { kampus UKI sangat menyenangkan. }\end{array}$ & $\mathbf{0}$ & $\mathbf{0}$ & 7 & 9 & 57 & $\begin{array}{c}3.5 \\
6\end{array}$ \\
\hline 1.3 & $\begin{array}{l}\text { Program tutorial mata kuliah Etika Kristen yang diadakan oleh } \\
\text { kampus UKI sangat membosankan. }\end{array}$ & 6 & 10 & $\mathbf{0}$ & $\mathbf{0}$ & 26 & $\begin{array}{c}1.6 \\
3\end{array}$ \\
\hline 1.4 & $\begin{array}{l}\text { Melalui program tutorial mata kuliah Etika Kristen dapat } \\
\text { memberikan petunjuk bagi saya sehingga saya belajar secara } \\
\text { efektif dan efisien. }\end{array}$ & $\mathbf{0}$ & $\mathbf{0}$ & 10 & 6 & 54 & $\begin{array}{c}3.3 \\
8\end{array}$ \\
\hline 1.5 & $\begin{array}{l}\text { Melalui program tutorial mata kuliah Etika Kristen dapat } \\
\text { mengarahkan saya pada tujuan hidup yang jelas dan pasti. }\end{array}$ & $\mathbf{0}$ & $\mathbf{0}$ & 8 & 8 & 56 & $\begin{array}{c}3.5 \\
0\end{array}$ \\
\hline 1.6 & $\begin{array}{l}\text { Melalui program tutorial mata kuliah Etika Kristen dapat } \\
\text { memotivasi saya untuk rajin belajar, rajin mengerjakan tugas- } \\
\text { tugas dan rajin mengikuti kuliah. }\end{array}$ & $\mathbf{0}$ & 1 & 9 & 6 & 53 & $\begin{array}{c}3.3 \\
1\end{array}$ \\
\hline
\end{tabular}




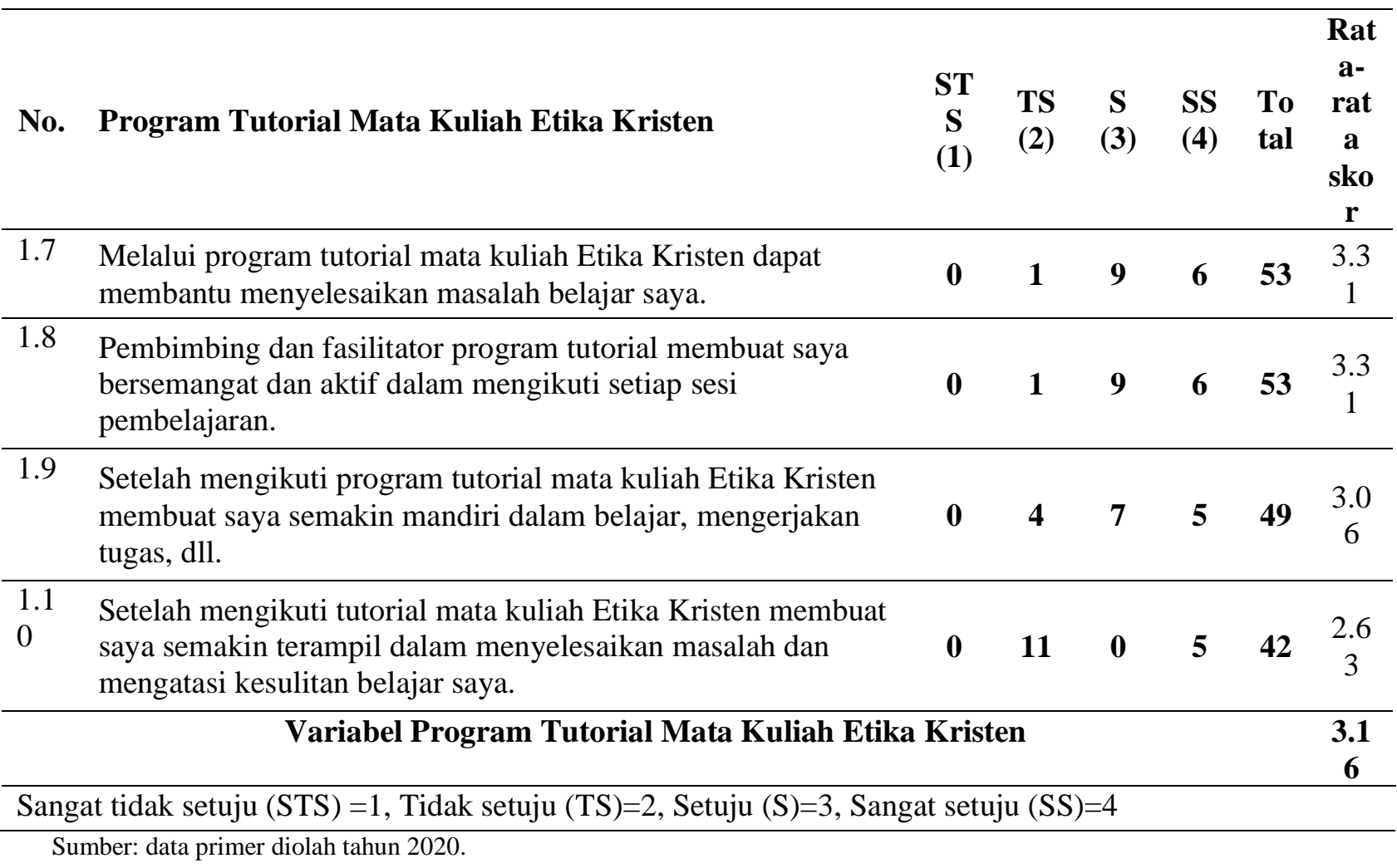

Berdasarkan hasil analisis deskriptif terhadap variabel Program Tutorial Mata Kuliah Etika Kristen yang ditunjukkan pada tabel di atas. diperoleh rata-rata skor sebesar 3.16, skor ini menunjukkan bahwa responden rata-rata memilih setuju dengan program tutorial yang diadakan oleh pihak kampus, tentunya program ini sangat bermanfaat bagi mereka sehingga mayoritas responden memberikan response yang baik atas program tersebut.

Program tutorial mata kuliah Etika Kristen yang diselenggarakan oleh Universitas Kristen Indonesia adalah untuk membentuk konsep diri mahasiswa dalam bersikap dan bertingkahlaku, baik di dalam lingkungan kampus maupun di luar lingkungan kampus. Dalam lingkungan kampus, mahasiswa diharapkan, mampu mempelajari setiap bahan mata kuliah yang diberikan oleh dosen, mahasiswa dapat bersosialisasi dan juga bergaul dengan siapa saja. Sedangkan di luar lingkungan kampus, mahasiswa diharapkan menjadi mahasiswa yang berkarkter dan berintegritas bagi sesamanya, terkhususnya bagi masyarakat sekitar dan juga mampu menerapkan setiap ilmu yang diperoleh dari kampus di dalam kehidupan mereka sehari-hari. Untuk hasil tanggapan ke-16 mahasiswa tersebut dapat dilihat pada tabel di bawah ini:

Tabel 3. Pembentukan Konsep Diri Mahasiswa

\begin{tabular}{|c|c|c|c|c|c|c|c|}
\hline No. & Pembentukan Konsep Diri Mahasiswa & $\begin{array}{r}\text { STS } \\
(1)\end{array}$ & $\begin{array}{l}\text { TS } \\
(2)\end{array}$ & $\begin{array}{c}\text { S } \\
(3)\end{array}$ & $\begin{array}{l}\text { SS } \\
(4)\end{array}$ & Total & $\begin{array}{r}\text { Rata- } \\
\text { rata } \\
\text { skor }\end{array}$ \\
\hline 1 & $\begin{array}{l}\text { Setelah mengikuti program tutorial mata kuliah Etika Kristen, } \\
\text { saya dapat mengenali diri saya secara utuh. }\end{array}$ & $\mathbf{0}$ & $\mathbf{0}$ & 10 & 6 & 54 & 3.38 \\
\hline 2 & $\begin{array}{l}\text { Setelah mengikuti program tutorial mata kuliah Etika Kristen, } \\
\text { saya berkomitmen untuk hidup sesuai dengan nilai-nilai } \\
\text { Alkitab. }\end{array}$ & $\mathbf{0}$ & $\mathbf{0}$ & 10 & 6 & 54 & 3.38 \\
\hline
\end{tabular}


1383 Program Tutorial Mata Kuliah Etika Kristen sebagai Pembentukan Konsep Diri Mahasiswa - Esther Rela Intarti, Noh Ibrahim Boiliu

DOI: https://doi.org/10.31004/basicedu.v6i1.1721

\begin{tabular}{|c|c|c|c|c|c|c|c|}
\hline No. & Pembentukan Konsep Diri Mahasiswa & $\begin{array}{r}\text { STS } \\
(\mathbf{1})\end{array}$ & $\begin{array}{l}\text { TS } \\
(2)\end{array}$ & $\begin{array}{l}\mathbf{S} \\
(3)\end{array}$ & $\begin{array}{l}\text { SS } \\
(4)\end{array}$ & Total & $\begin{array}{r}\text { Rata- } \\
\text { rata } \\
\text { skor }\end{array}$ \\
\hline 3 & $\begin{array}{l}\text { Setelah mengikuti program tutorial mata kuliah Etika Kristen, } \\
\text { saya berkomitmen untuk hidup sesuai dengan kehendak } \\
\text { Tuhan. }\end{array}$ & $\mathbf{0}$ & $\mathbf{0}$ & 10 & 6 & 54 & 3.38 \\
\hline 4 & $\begin{array}{l}\text { Saya sangat terinspirasi untuk mencapai cita-cita saya setelah } \\
\text { mengikuti program tutorial mata kuliah Etika Kristen. }\end{array}$ & $\mathbf{0}$ & 3 & 8 & 5 & 50 & 3.13 \\
\hline 5 & $\begin{array}{l}\text { Saya semakin percaya diri setelah mengikuti program tutorial } \\
\text { mata kuliah Etika Kristen. }\end{array}$ & $\mathbf{0}$ & 2 & 9 & 5 & 51 & 3.19 \\
\hline 6 & $\begin{array}{l}\text { Saya semakin bersemangat dalam belajar, mengerjakan tugas } \\
\text { dan mengikuti perkuliahan setelah mengikuti program } \\
\text { tutorial mata kuliah Etika Kristen. }\end{array}$ & $\mathbf{0}$ & 3 & 9 & 4 & 49 & 3.06 \\
\hline 7 & $\begin{array}{l}\text { Saya semakin optimis untuk menjadi orang sukses setelah } \\
\text { mengikuti program tutorial mata kuliah Etika Kristen. }\end{array}$ & $\mathbf{0}$ & 1 & 10 & 5 & 52 & 3.25 \\
\hline 8 & $\begin{array}{l}\text { Setelah mengikuti program mata kuliah Etika Kristen, saya } \\
\text { semakin mengenali akan panggilan Kristus di dalam } \\
\text { kehidupan saya. }\end{array}$ & $\mathbf{0}$ & 1 & 10 & 5 & 52 & 3.25 \\
\hline 9 & $\begin{array}{l}\text { Setelah mengikuti program tutorial mata kuliah Etika Kristen, } \\
\text { saya dapat merealisasikannya secara nyata melalui pelayanan } \\
\text { di gereja, sekolah, panti asuhan, dll. }\end{array}$ & 0 & 1 & 12 & 3 & 50 & 3.13 \\
\hline 10 & $\begin{array}{l}\text { Setelah mengikuti program mata kuliah Etika Kristen, } \\
\text { membantu saya untuk menjadi agen perubahan bagi orang } \\
\text { lain. }\end{array}$ & 0 & 0 & 13 & 3 & 51 & 3.19 \\
\hline & \multicolumn{6}{|l|}{ Membentuk Konsep Diri Mahasiswa } & 3.23 \\
\hline & ak setuju $($ STS $)=1$, Tidak setuju $($ TS $)=2$, Setuju $(S)=$ & iga & & $=4$ & & & \\
\hline
\end{tabular}

Berdasarkan hasil analisis deskriptif terhadap Pembentuk Konsep Diri Mahasiswa melalui Program Tutorial Mata Kuliah Etika Kristen yang ditunjukkan pada tabel di atas, diperoleh rata-rata skor sebesar 3.23, skor ini menunjukkan bahwa responden rata-rata menjawab setuju dengan program tutorial yang diadakan oleh pihak kampus, karena Program tutorial mata kuliah Etika Kristen yang diselenggarakan oleh Universitas Kristen Indonesia adalah untuk membentuk konsep diri mereka dalam bersikap dan bertingkahlaku, baik di dalam lingkungan kampus maupun di luar lingkungan kampus.

Program Tutorial mata kuliah Etika Kristen dirancang untuk membentuk konsep diri mahasiwa dalam bersikap dan bertingkahlaku. Berdasarkan analisis dari 7 pertanyaan yang diajukan terhadap tanggapan 3 narasumber tentang program tutorial mata kuliah Etika Kristen, diperoleh informasi bahwa:

1. Bagaimana pendapat Anda tentang program tutorial mata kuliah Etika Kristen yang diadakan oleh Universitas Kristen Indonesia yang bertujuan untuk membentuk konsep diri mahasiswa? Apa urgensi dan manfaat dari program tersebut?

Hasil analisis: ke-3 narasumber menjawab bahwa program tutorial etika Kristen adalah program yang baik karena telah dirancang untuk membentuk konsep diri mahasiswa dan bermanfaat untuk membentuk karakter mahasiswa.

2. Sejauhmana efektivitas relevansi pelaksanaan tutorial dengan mata kuliah Etika Kristen dalam membentuk konsep diri mahasiswa di Universitas Kristen Indonesia? Apakah materi penyelenggaraan tutorial sudah memenuhi sasaran dan tujuan yang akan dicapai? 
1384 Program Tutorial Mata Kuliah Etika Kristen sebagai Pembentukan Konsep Diri Mahasiswa - Esther Rela Intarti, Noh Ibrahim Boiliu

DOI: https://doi.org/10.31004/basicedu.v6i1.1721

Hasil analisis: ke-3 narasumber menjawab bahwa materi tutorial etika Kristen sudah berjalan dengan baik, hasil evaluasi tutorial menunjukkan bahwa mahasiswa menunjukkan sikap-sikap positif seperti tujuan tutorial sebab mahasiswa memahami dengan baik materi tutorial.

3. Apakah pendamping/ asisten tutorial (mahasiswa senior) sudah mumpuni dalam pendampingan pelaksanaan tutorial Etika Kristen dan bagaimana pendapat Anda? Apa dan bagaimana input, proses dan output dari program tutorial mata kuliah Etika Kristen yang diadakan oleh Universitas Kristen Indonesia dalam membentuk konsep diri mahasiswa?

Hasil analisis: ke-3 narasumber menjawab bahwa pengajar mata kuliah Etika Kristen adalah dosen yang berpengalaman dan juga adalah para rohaniawan Kristen, sedangkan mahasiswa senior yang ditugaskan sebagai pendamping atau asisten tutorial (astor) telah melewati proses seleksi dan pemilihan yang baik oleh tim mata kuliah.

4. Hasil/ output seperti apakah yang diharapkan oleh Universitas Kristen Indonesia tentang program tersebut? Bagaimana implementasinya setelah mahasiswa mengikuti program tersebut?

Hasil analisis: ke-3 narasumber menjawab bahwa mahasiswa UKI menjadi pribadi yang cerdas secara emosional intelegensi dan spiritual dan mampu memberikan pengaruh kepada lingkungan di mana pun mereka berada, memanfaatkan waktu kuliah dengan baik, yakni terlibat dalam kegiatan tutorial sehingga dapat membentuk karakter mahasiswa. Ini akan memberikan dampak positif pada masyarakat.

5. Bagaimana pendapat Anda tentang gambaran konsep diri mahasiswa Universitas Kristen Indonesia sebelum dan sesudah mengikuti program tutorial mata kuliah Etika Kristen?

Hasil analisis: ke-3 narasumber menjawab bahwa perlu dilakukan follow up dan observasi sehingga tutorial yang dilaksanakan dapat bermanfaat.

6. Apa dampak nyata dari program tutorial mata kuliah Etika Kristen bagi Universitas Kristen Indonesia? Hasil analisis: ke-3 narasumber menjawab bahwa sikap yang menghargai kesepakatan bersama, disiplin (walau perlu ditingkatkan), mulai terlihat menjadi proaktif, dan melalui diskusi dan sedikit perdebatan, perlahan mau memahami serta menerima perbedaan satu sama lain, dan keharmonisan antar mahasiswa.

7. Evaluasi apa yang dipandang penting yang harus dilakukan oleh Universitas Kristen Indonesia dalam penyelenggaraan program tutorial Etika Kristen?

Hasil analisis: ke-3 narasumber menjawab bahwa harus dilakukan pembinaan bagi mahasiswa dari daerah 3T, misalnya Papua, Nias, Mentawai; pembelajaran di luar kelas ataupun kokurikuler perlu ditingkatkan sebagai enrichment dari tutorial dan dimasukkan dalam roadmap penelitian universitas agar menjadi perhatian khusus terhadap perkembangan karakter mahasiswa.

Program tutorial mata kuliah Etika Kristen yang diselenggarakan oleh Universitas Kristen Indonesia adalah untuk membentuk konsep diri mahasiswa dalam bersikap dan bertingkahlaku, baik di dalam lingkungan kampus maupun di luar lingkungan kampus. Dalam lingkungan kampus, mahasiswa diharapkan, mampu mempelajari setiap bahan mata kuliah yang diberikan oleh dosen, mahasiswa dapat bersosialisasi dan juga bergaul dengan siapa saja. Sedangkan di luar lingkungan kampus, mahasiswa diharapkan menjadi mahasiswa yang berkarkter dan berintegritas bagi sesamanya, terkhususnya bagi masyarakat sekitar dan juga mampu menerapkan setiap ilmu yang diperoleh dari kampus di dalam kehidupan mereka sehari-hari.

Berdasarkan hasil analisis deskriptif terhadap variabel Pembentuk Konsep Diri Mahasiswa melalui Program Tutorial Mata Kuliah Etika Kristen diperoleh rata-rata skor sebesar 3.23. Skor ini menunjukkan bahwa responden rata-rata menjawab setuju dengan program tutorial yang diadakan oleh pihak kampus, karena program tutorial mata kuliah Etika Kristen yang diselenggarakan oleh Universitas Kristen Indonesia adalah untuk membentuk konsep diri mahasiswa/I dalam bersikap dan bertingkahlaku, baik di dalam lingkungan kampus maupun di luar lingkungan kampus. 
1385 Program Tutorial Mata Kuliah Etika Kristen sebagai Pembentukan Konsep Diri Mahasiswa - Esther Rela Intarti, Noh Ibrahim Boiliu

DOI: https://doi.org/10.31004/basicedu.v6i1.1721

Berdasarkan hasil analisis, para mahasiswa, pengurus UPKK Universitas Kristen Indonesia dan dosen mata kuliah Etika Kristen tentang Program Tutorial Mata Kuliah Etika Kristen Dalam Membentuk Konsep Diri Mahasiswa. Tentunya program yang diselenggarakan oleh Universitas Kristen Indonesia ini merupakan program yang sangat bermanfaat bagi para mahasiswa baru. Tujuan pelaksanaan kegiatan Tutorial Etika Kristen ini merupakan program yang dirancang untuk membentuk para mahasiswa tersebut agar mereka menjadi pribadi yang berkarakter dan berintegritas sesuai dengan nilai-nilai Kristen. Membentuk mereka menjadi pribadi yang mandiri dan bertanggungjawab atas dirinya terkhususnya saat mereka menjalani kegiatan perkuliahan di kampus. Menurut Oemar Hamalik (1994, 158-160) bahwa program tutorial yang diselenggarakan tentunya memiliki fungsi yaitu:

1. Instruksional, yakni melaksanakan proses pembelajaran agar para siswa belajar mandiri melalui modul yang telah ditetapkan

2. Diagnosis-bimbingan yakni membantu para siswa mengalami kelemahan, kekuatan, kelambanan, masalah dalam mempelajari modul berdasarkan hasil penilaian, baik formatif, maupun sumatif sehingga siswa siswa mampu membimbing diri sendiri.

3. Personal, yakni memberikan keteladanan kepada siswa seperti penguasaan materi modul, cara belajar, sikap dan perilaku yang secara tak langsung menggugah motivasi belajar mandiri dan motif berprestasi.

Selain fungsi program tutorial yang dijelaskan di atas juga Oemar Hamalik menegaskan bahwa untuk program tutorial yang diselenggarkan perlu adanya tujuan yang jelas yaitu:

1. Untuk meningkatkan penguasaan pengetahuan para masiswa sesuai dengan materi yang relevan.

2. Untuk meningkatkan keterampilan mahasiswa tentang cara memecahkan masalah, mengatasi kesulitan atau hambatan agar mampu membimbing diri sendiri.

3. Untuk meningkatkan kemampuan mahasiswa tentang cara belajar mandiri dan menerapkannya di dalam kehidupannya sehari-hari.

Dari penjelasan di atas jika dikaitkan dengan program tutorial mata kuliah Etika Kristen yang diadakan oleh Universitas Kristen Indonesia sudah berjalan dengan baik dan efektif. Hal ini dapat dilihat pada hasil analisis deskriptif variabel penelitian di atas dan juga hasil tanggapan dari setiap informan yang telah diuraikan sebelumnya bahwa:

1. Program tutorial mata kuliah Etika Kristen di UKI sudah dirancang dengan baik oleh tim, dengan tujuan membentuk konsep diri mahasiswa. Hasil pencapaian dapat dilihat secara langsung melalui refleksi diri dari setiap mahasiswa. Selanjutnya dilengkapi dengan pelayanan kepada masyarakat, sehingga mahasiswa dapat belajar secara teori dan mempraktikkan melalui pelayanan masyarakat.

2. Program yang sangat baik untuk membantu mahasiswa lebih mengenali diri mereka sendiri dan juga tujuan dan maksud Tuhan menciptakan mereka sebagai bekal menjalani masa pendidikan sebelum mereka bekerja.

3. Bahwa program ini sangat baik karena mahasiswa dapat mengenal siapa dirinya dan siapa Tuhannya dengan baik sehingga pada akhirnya mereka dapat menemukan tujuan hidup yang bermakna dan berarti bagi kehidupan mereka.

4. Program ini sangat baik sebagai komunitas pertama bagi mahasiswa baru UKI untuk membentuk konsep diri mereka yang benar berdasarkan nilai-nilai Kristiani karena di era seperti ini banyaknya distraksi dari kemajuan zaman membuat anak-anak muda mengukur nilai dirinya berdasarkan pengakuan dari orang lain misal; pujian orang-orang di sosial media, banyaknya teman yang dimiliki, selalu ingin menampilkan bagian diri yang terbaik agar diterima oleh lingkungan, dll.

Pada akhir pembelajaran Tutorial Etika Kristen para mahasiswa diberi tugas melaksanakan kegiatan dalam bentuk service learning. Tujuan service learning ini adalah pembelajaran bagi mahasiswa baru untuk 
merefleksikan secara langsung dari materi yang telah dipelajarinya dalam bentuk sebuah pelayanan yang berorientasi kepada empati bagi sesama. Pada akhir puncak kegiatan tutorial dan Etika Kristen, UPKK membuat sebuah ibadah pengutusan bagi peserta mata kuliah Etika Kristen dan Tutorial Etika Kristen. Dalam ibadah ini para peserta diutus dan ditantang untuk merealisasikan materi-materi etika yang telah dipelajarinya dalam aksi nyata bagi sesama dan ungkapan syukur kepada Tuhan. Contoh: dengan mengunjungi panti asuhan, rumah jompo, panti rehabilitasi narkoba, gereja dan sekolah, memberikan penyuluhan kesehatan dan kebersihan lingkungan dan lainnya, sehingga mahasiswa dapat merasakan dan mempraktikkan secara langsung bagaimana kenyataan di lapangan dapat memberikan nilai-nilai untuk mahasiswa dan kehidupannya kelak untuk dipraktikkan.

Penelitian ini memberikan sumbangsih bagi moral, karakter, sikap, kemampuan berefleksi, pengenalan diri, dan keputusan-keputusan etis. Program tutorial membantu mahasiswa mengenali kelemahan-kelemahan untuk mengatasinya.

Berdasarkan pengalaman dalam pelaksanaan penelitian ini, ada beberapa keterbatasan yang dialami dan dapat menjadi perhatian untuk peneliti-peneliti yang akan datang. Beberapa keterbatasan dalam penelitian ini, antara lain: 1) Tidak semua program studi dari 8 fakultas terwakili sebagai responden. 2) Data atau informasi dari mahasiswa hanya dilakukan melalui google form sehingga tidak memperoleh informasi yang komprehensif.

\section{KESIMPULAN}

Berdasarkan hasil analisis deskriptif variabel penelitian dan hasil wawancara yang dilakukan tentang Program Tutorial Mata Kuliah Etika Kristen Dalam Membentuk Konsep Diri Mahasiswa maka pada bagian ini peneliti menyimpulkan bahwa: 1) Program tutorial mata kuliah Etika Kristen di UKI sudah dirancang dengan baik oleh tim, dengan tujuan membentuk konsep diri mahasiswa. Hasil pencapaian dapat dilihat secara langsung melalui refleksi diri dari setiap mahasiswa. 2) Program tutorial mata kuliah Etika Kristen di UKI membantu mahasiswa lebih mengenali diri sendiri sesuai tujuan dan maksud diciptakan Tuhan, dan sebagai bekal menjalani masa pendidikan sebelum mereka bekerja. 3) Program tutorial mata kuliah Etika Kristen di UKI membantu menemukan tujuan hidup yang bermakna dan berarti bagi kehidupan. 4) Program tutorial mata kuliah Etika Kristen di UKI membantu mahasiswa baru menyesuaikan diri di komunitas UKI. 5) Melakukan follow up dan observasi sehingga tutorial yang dilaksanakan dapat bermanfaat.

\section{UCAPAN TERIMA KASIH}

Kami menyampaikan terima kasih kepada Universitas Kristen Indonesia yang telah mendanai penelitian kami. Kepada Tim LPPM Universitas Kristen Indonesia yang telah mendampingi dalam proses penelitian, mulai dari presentasi proposal penelitian hingga presentasi hasil penelitian. Kami juga berterima kasih pada Prodi Pendidikan Agama Kristen tempat kami berkarya.

\section{DAFTAR PUSTAKA}

Awang, J. A., Prayitno, I. S. P., \& Engel, J. D. (2021). Strategi Pendidikan Agama Kristen Bagi Remaja Dalam Membentuk Konsep Diri Guna Menghadapi Krisis Identitas Akibat Penggunaan Media Sosial. Kharismata: Jurnal Teologi Pantekosta, 4(1), 98-114. Https://Doi.Org/10.47167/Kharis.V4i1.64

Badan Pengembangan Bahasa Dan Perbukuan, K. P. Dan K. R. I. (2016). Kamus Besar Bahasa Indonesia. Bettler, J. F. (1984). Gaining An Accurate Self-Image-Part Ii. The Journal Of Pastoral Practice, Vii(1). 
1387 Program Tutorial Mata Kuliah Etika Kristen sebagai Pembentukan Konsep Diri Mahasiswa - Esther Rela Intarti, Noh Ibrahim Boiliu

DOI: https://doi.org/10.31004/basicedu.v6i1.1721

Boiliu, N. I., \& Samosir, C. M. (2019). Manusia Sebagai Makhluk Moral Dalam Perspektif Teologia Pendidikan Johann Heinrich Pestalozzi. Jurnal Dinamika Pendidikan, 12(3), 187-197.

Boiliu, N. I., Widjaja, F. I., Nugroho, F. J., Siahaan, H. E., \& Harefa, O. (2020). Pendidikan Humanis Sebagai Pendekatan Pembelajaran Di Era Revolusi Industri 4.0. In Sosial, Pendidikan Dan Agama Sebagai Pondasi Dalam Mewujudkan "Maju Bersama Kita Berjaya” (Pp. 741-758). Marpoyan Tujuh.

Boiliu, N., Samosir, C., \& Nugroho, A. (2020). Human Value In The Disruption Era: Analysis Of The Paulo Freire Education Philosophy And Genesis 1:26,27. Https://Doi.Org/10.4108/Eai.11-12-2019.2302086

Cahyono. (2004). Evaluasi Pelaksanaan Seven Jumps Dalam Diskusi Tutorial Mahasiswa Psik Program A Fakultas Kedokteran Universitas Gajah Mada. Psik Fakultas Kedokteran Universitas Gajah Mada.

Demak, I. P. K., \& Paulus, E. R. (2014). Hubungan Persepsi Mahasiswa Terhadap Peran Tutor Pada Tutorial Dengan Prestasi Belajar Di Program Studi Pendidikan Dokter Fakultas Kedokteran Dan Ilmu Kesehatan Universitas Tadulako. Jurnal Ilmiah Kedokteran, 1(3), 48-55.

Dupe, S. I. S. (2020). Konsep Diri Remaja Kristen Dalam Menghadapi Perubahan Zaman. Jurnal Ilmiah Religiosity Entity Humanity (Jireh), 2(1), 53-69. Https://Doi.Org/10.37364/Jireh.V2i1.26

Gebauer, J. E., Sedikides, C., Schrade, A., \& Self-Enhancement, C. (2017). Christian Self-Enhancement. 113(5), 786-809.

Hamalik, O. (1994). Sistem Pembelajaran Jarak Jauh Dan Pembinaan Ketenagaan. Trigenda Karya.

Harsono, Yohannes, H. C., \& Sudjarwadi. (2005). Tutorial (G. R. Rahayu (Ed.)). Pusat Pengembangan Pendidikan Universitas Gadjah Mada.

Hoekeman, A. A. (2018). Manusia Ciptaan Menurut Gambar Allah. Momentum.

Jordan, J., Leliveld, M. C., \& Tenbrunsel, A. E. (2015). The Moral Self-Image Scale: Measuring And Understanding The Malleability of The Moral Self. Frontiers In Psychology, 6(Dec). Https://Doi.Org/10.3389/Fpsyg.2015.01878

Kurniawan, N. (2000). Membangun Konsep Diri Berdasarkan Firman Tuhan. Veritas: Jurnal Teologi Dan Pelayanan, 1(2), 215-222. Https://Doi.Org/10.36421/Veritas.V1i2.37

Mackenna, C. (2002). Self Images And God Images. British Journal Of Psychotherapy, 18(3), 325-338. Https://Doi.Org/10.1111/J.1752-0118.2002.Tb00034.X

Marija, P., Kawangung, Y., \& Kause, M. (2019). Pendekatan Humanis-Relegius Pada Pendidikan Kristen Sebagai Pembentukan Karakter Generasi Milenial. Jurnal Teruna Bhakti, 2(1).

Matondang, S. (2018). Memahami Identitas Diri Remaja Dalam Kristus Menurut Efesus 2:1-10. Illuminate Jurnal Teologi Dan Pendidikan Kristiani, 1(1), 105-124.

Moleong, L. (2018). Metodologi Penelitian Kualitatif. Rosdakarya.

Neny, T. (2018). Interprofessional Education. Deepublish Publishers.

Neolaka, A., \& Neolaka, G. A. A. (2017). Landasan Pendidikan Dasar Pengenalan Diri Sendiri Menuju Perubahan Hidup. Kencana.

Norman, W. H. (1977). Improving Your Self Image. Harvest House Pub.

Nuurjannah, F. A. (2020). Pembelajaran Tutorial Dengan Kemampuan Berpikir Kritis Mahasiswa Di Program Studi D3 Kebidanan Unpad. Jurnal Jkft, Http://Jurnal.Umt.Ac.Id/Index.Php/Jkft/Article/View/2804

Secor, C. (2020). Imago Dei-In The Image Of God. Journal Of Christian Nursing : A Quarterly Publication Of Nurses Christian Fellowship, 37(4), 201. Https://Doi.Org/10.1097/Cnj.0000000000000773

Situmorang, A. G., Sipayung, R., Simarmata, E. J., \& Silaban, P. J. (2020). Hubungan Antara Konsep Diri Dengan Hasil Belajar Siswa Pada Siswa Sekolah Dasar. Jurnal Basicedu, 4(4), 1358-1362. 
1388 Program Tutorial Mata Kuliah Etika Kristen sebagai Pembentukan Konsep Diri Mahasiswa - Esther Rela Intarti, Noh Ibrahim Boiliu

DOI: https://doi.org/10.31004/basicedu.v6i1.1721

Https://Doi.Org/10.31004/Basicedu.V4i4.547

Sumiharsono, R., \& Hasanah, H. (2018). Media Pembelajaran: Buku Bacaan Wajib Dosen, Guru Dan Calon Pendidik. Pustaka Abadi.

Suroso, A. (1992). Studi Analisis Persepsi Dan Kompetensi Tutor Tentang Penggunaan Teknik Bertanya Dalam Kegiatan Tutorial Ut. Pusat Penelitian Kelembagaan, Lembaga Penelitian Universitas Terbuka.

Szcześniak, M., \& Timoszyk-Tomczak, C. (2020). Religious Struggle And Life Satisfaction Among Adult Christians: Self-Esteem As A Mediator. Journal Of Religion And Health, 59(6), 2833-2856. Https://Doi.Org/10.1007/S10943-020-01082-9

Thornton, L. R. (1985). A Biblical Philosophy Of Self-Image An Individual Needs To Regard Himself As Capable , Significant, Successful And. Calvary Baptist Theological Journal, 26-34.

Tong, S. (2009). Peta Teladan Allah. Momentum.

Wells, D. F. (1983). Self-Esteem: The New Confusion. The Reformed Journal. 